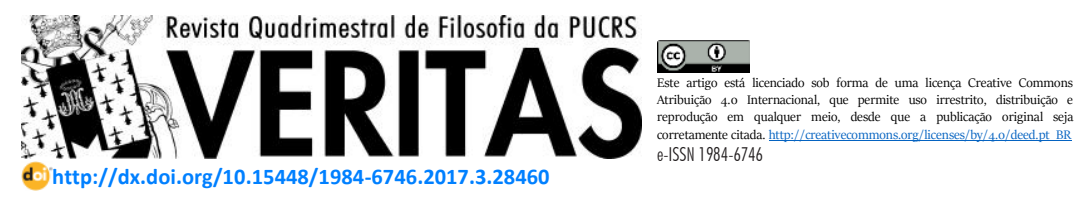

\title{
Um problema para a epistemologia anti-sorte de Pritchard
}

A problem for Pritchard's antiluck epistemology.

Lucas Roisenberg Rodrigues ${ }^{1}$

\begin{abstract}
Resumo: Este artigo propõe uma crítica à epistemologia anti-sorte, tal como defendida por Duncan Pritchard. A teoria de Pritchard é uma das mais bem desenvolvidas explorações do conceito de sorte, e da sua significação epistêmica. Ele julga possível derivar uma condição que exclua a sorte epistêmica a partir de uma análise modal do conceito de sorte. A cláusula epistêmica resultante é uma condição denominada princípio de segurança. Após apresentar a teoria e algumas de suas motivações, argumento que ela não consegue responder a uma objeção apresentada por Mark McEvoy, e que consiste em uma variação do exemplo da loteria. Por fim, alego que o princípio de segurança, tal como defendido por Pritchard, não captura corretamente nossas intuições sobre quando sorte está ausente ou presente.
\end{abstract}

Palavras-chave: análise do conhecimento; sorte epistêmica; sorte; segurança.

\begin{abstract}
The article is a critique to Pritchard's antiluck epistemology. Pritchard's theory is one of the most developed explorations on the concepct of luck, and its epistemic significance. He thinks it's possible to derive a condition that excludes epistemic luck from a modal analysis of the concept of luck. The epistemic condition that it's produced from such process is the so called safety principle. After I explain Pritchard's theory and some of it's motivations, I argue that the author can't respond to an objection by Mark McEvoy, a variation on a lottery example. I also claim that safety principle doesn't grasp correctly our intuitions about when epistemic luck is present or absent.
\end{abstract}

Keywords: Knowledge analysis; epistemic luck; luck; safety.

\section{Introdução}

A tese de que conhecimento é incompatível com a presença de sorte na formação da crença verdadeira é um dos pilares da história da epistemologia ${ }^{2}$. A incompatibilidade é detectável em situações diversas,

\footnotetext{
${ }^{1}$ Doutorado em filosofia pela PUCRS. Professor de filosofia na Universidade Federal Da Fronteira Sul (UFFS) < lucasroisenberg@gmail.com >

${ }^{2}$ Diversos autores, recentes e mais antigos, afirmaram a tese da incompatibilidade entre sorte e conhecimento. Bertrand Russel, por exemplo, perguntou retoricamente: "em outras palavras, podemos saber alguma coisa, ou apenas por uma feliz coincidência acreditamos no que é verdadeiro?” (RUSSEL, 2001, p.76). Mais explicitamente, por exemplo, Jonathan Dancy afirmou: "justificação e conhecimento, de alguma forma, não devem depender de uma
} 
notadamente nos denominados casos Gettier. Em um curto artigo com não mais de 3 páginas, Gettier (1963) produziu contraexemplos à denominada análise tradicional do conhecimento, segundo a qual conhecimento é crença verdadeira e justificada. Desde então, foram muitas as tentativas de identificar o que há de equivocado com esta análise tradicional e como ela deve ser corrigida, ou eventualmente substituída por uma proposta radicalmente diferente ${ }^{3}$. Como é bem conhecido, esse segue sendo um dos tópicos mais controversos e complicados da agenda epistemológica contemporânea, mesmo passados mais de cinquenta anos desde o artigo de Gettier.

Consideremos uma variação dos exemplos de Gettier, que denominaremos de caso do relógio parado ${ }^{4}$. João acredita que são 11 horas porque os ponteiros do seu relógio indicam que são 11 horas. A sua crença é verdadeira, pois são 11 horas. Ao mesmo tempo, João possui justificação para crer que são onze horas: o relógio sempre funcionou corretamente até o presente momento, seus sentidos parecem estar em perfeita ordem, não parece haver nada de anormal na situação, e assim por diante. Todavia, inesperadamente, ocorreu a coincidência de que relógio de João parou de funcionar precisamente às 11 horas da noite anterior. Ainda que a crença de João a respeito do horário seja verdadeira e justificada, não é correto que João possui conhecimento: ninguém sabe o horário consultando um relógio quebrado, ainda que o relógio aponte coincidentemente o horário correto. A lição que estes e outros exemplos parecem indicar é justamente esta: conhecimento é incompatível com sorte ${ }^{5}$.

No entanto, apesar desta ter se tornado uma espécie de lugarcomum, não foram muitos que tentaram elaborar de maneira detalhada o que está envolvido na tese da incompatibilidade entre sorte e conhecimento. Duncan Pritchard foi o filósofo contemporâneo que mais

\footnotetext{
coincidência ou sorte" (DANCY, 1985, p. 134). Peter Unger, por sua vez, afirmou: "para qualquer valor sentencial de $\mathrm{p}$, a crença de um homem de que p é uma instância de que p somente se não é um acidente que a crença do homem é verdadeira” (UNGER, 1968, p.157).

${ }^{3}$ Para uma análise bastante extensa das primeiras respostas ao problema ao problema Gettier, conferir Shope (1984).

4 Exemplo formulado a partir de Russel (1948, p.170). No contexto em que foi apresentado por Russel, o caso do relógio foi construído para explicar porque conhecimento é distinto de crença verdadeira. No entanto, é possível, com mínimas modificações, transformar o exemplo em um caso Gettier, que é precisamente o que fizemos aqui.

${ }^{5} \mathrm{O}$ primeiro filósofo que entendeu explicitamente as objeções de Gettier dessa maneira foi Unger (1968). Desde então, é praxe compreender o problema sob esta perspectiva.
} 
longamente refletiu sobre a natureza da sorte epistêmica, e que defendeu uma teoria detalhada e instigante da natureza da sorte, e das sua relações com o conhecimento. O autor propõe um projeto filosófico amplo, denominado epistemologia anti-sorte, o qual toma o conceito de sorte como uma espécie de âncora, do qual podemos derivar condições necessárias para o conhecimento e iluminar diferentes problemas epistemológicos.

Pritchard (2012a), distingue entre dois tipos de epistemologia anti-sorte. A epistemologia anti-sorte modesta afirma que existe uma condição anti-sorte, necessária para a posse de conhecimento, e procura derivar uma condição necessária, porém não suficiente, para o conhecimento a partir do conceito de sorte. A epistemologia anti-sorte robusta afirma que a condição anti-sorte, conjuntamente com a crença e a verdade, é necessária e suficiente para a posse de conhecimento. Conforme veremos a seguir, Pritchard é partidário da epistemologia anti-sorte modesta. Mais especificamente, ele pensa que a condição anti-sorte deve ser combinada com uma cláusula de habilidade.

O projeto da epistemologia anti-sorte de Pritchard é desenvolvido em três etapas:

1) Análise do conceito de sorte;

2) Análise do conceito de sorte epistêmica;

3) Especificação de uma condição anti-sorte para o conhecimento.

A seguir, iremos explicar como Pritchard aborda o conceito de sorte, e posteriormente a derivação de uma cláusula anti-sorte para o conhecimento.

\section{Sorte segundo Pritchard}

Embora o conceito de sorte seja frequentemente empregado na literatura epistemológica pós-Gettier, pouco foi feito para explicar em que consiste o conceito propriamente dito. Diferentemente das teorias mais conhecidas e tradicionais, Pritchard oferece uma análise mais detalhada do conceito. Ele propõe uma análise do conceito em termos estritamente modais, o que permite, conforme veremos mais tarde, gerar uma cláusula anti-sorte também modal. 
Sorte, segundo Pritchard (2005, p.128-132), pode ser caracterizada pela combinação de dois princípios. O primeiro destes princípios é o seguinte:

$\left(L_{1}\right)$ se um evento E é um caso de sorte no mundo atual, então E não ocorre em uma ampla classe dos mundos mais próximos ao mundo atual, nas quais as condições iniciais relevantes são as mesmas.

Pritchard entende proximidade como uma relação de similaridade entre mundos possíveis ${ }^{6}$. Mundos possíveis podem ser ordenados em relação a um determinado mundo possível sob avaliação. A ordem reflete o grau de proximidade em relação ao mundo de consideração: quanto mais similar, mais próximo ao mundo possível em questão.

O segundo princípio, que visa introduzir a noção de relevância para um agente, é o seguinte:

$\left(\mathbf{L}_{2}\right)$ se um evento E é um caso de sorte, então E é significativo para um agente $\mathrm{S}$ em consideração (ou seria significativo, se $\mathrm{S}$ avaliasse os fatos relevantes) ${ }^{7}$.

Uma vez estabelecidos estes princípios, Pritchard passa a esclarecer porque ambos parecem dar conta de nossas atribuições de sorte em situações relevantes. Consideremos algumas situações paradigmáticas de atribuição de sorte: ganhar em uma loteria, encontrar um objeto valioso e escapar de um acidente (por exemplo, de avião ou de carro).

Um sujeito $\mathrm{S}$ compra um bilhete de loteria, e, para a sua surpresa e felicidade, descobre que seu bilhete foi sorteado. Como na maioria das loterias, supomos que a loteria era justa e os bilhetes em competição eram muitos. Intuitivamente, diríamos que $\mathrm{S}$ teve sorte neste caso (muita sorte, se quisermos ser ainda mais enfáticos).

Os princípios $L_{1}$ e $L_{2}$ geram precisamente o resultado que esperávamos nestas circunstâncias. A imensa maioria dos mundos próximos ao mundo atual em que as condições relevantes iniciais são mantidas constantes, S não seria sorteado. Existe uma certa periferia ou cinturão de mundos ao redor do mundo atual, e apenas em uma mísera

\footnotetext{
${ }^{6}$ A explicação dos contrafactuais em termos uma semântica de mundos possíveis e da noção de similaridade foi desenvolvida por Lewis(1973) e Stalnaker(1981). Infelizmente, Pritchard não desenvolve em maiores detalhes o que entende por "similaridade".

${ }^{7}$ A noção de relevância, contida no princípio $\mathrm{L}_{2}$, inclui interesses de diferentes ordens: prudenciais, morais ou epistêmicos. Não há restrição a interesses epistêmicos, quando tratamos da noção genérica de sorte. Todavia, quando tratarmos da sorte propriamente epistêmica, os interesses relevantes devem ser do tipo epistêmico.
} 
fração destes mundos o bilhete de S foi sorteado. Na maioria destes, $\mathrm{S}$ comprou o bilhete e ele não foi sorteado. Obviamente, o princípio $\mathrm{L}_{2}$ também é satisfeito, em razão da vantagem pecuniária.

Pritchard também menciona o caso de um sujeito $\mathrm{S}$ que, sem ter planejado encontra um objeto de alto valor aquisitivo escondido em algum lugar. O sujeito $\mathrm{S}$ teve sorte em en-contrar o objeto escondido. Em uma grande porção dos mundos próximos em que as circunstâncias iniciais são mantidas fixas, ele não encontra nenhum objeto. Isto é algo muito difícil de acontecer nas circunstâncias do exemplo, em que ele, sem qualquer intenção ou propósito, encontra um objeto escondido de alto valor.

Consideremos um terceiro exemplo, que é um dos casos mais comuns e emblemáticos de sorte, embora não seja tratado explicitamente por Pritchard. Um sujeito S compra uma passagem de avião. Todavia, em função de um congestionamento no trânsito não esperado, não consegue chegar a tempo de embarcar. $\mathrm{O}$ avião que ele iria tomar sofre um acidente e, como é comum em casos deste tipo, mata todos os passageiros. Nós diríamos que o sujeito $\mathrm{S}$ escapou de um acidente por sorte. Assim como nos casos anteriores, os princípios $\mathrm{L}_{1}$ e $\mathrm{L}_{2}$ também são satisfeitos. O evento $\mathrm{E}$, que podemos caracterizar como escapar do engarrafamento e chegar a tempo de embarcar no avião que sofreu o acidente, embora não ocorra no mundo atual, ocorre em uma classe ampla dos mundos próximos em que as condições relevantes iniciais são as mesmas. Afinal, na maioria dos mundos próximos em que as condições iniciais relevantes são mantidas constantes, o sujeito $S$ embarca no avião e perde sua vida. Ele quase perdeu a vida, nós diríamos, e este quase indica que ele muito facilmente poderia ter perdido a vida, mantidas as demais circunstâncias constantes (em um mundo muito próximo, ele teria perdido a vida). De forma semelhante, o princípio $L_{2}$ também é satisfeito, pelo evidente interesse de $S$ na preservação da sua vida.

Pela combinação de $L_{1}$ e $L_{2}$, temos a seguinte formulação do conceito de sorte:

Sorte - Um evento E ocorre por sorte no mundo atual se e somente se (i) E não ocorre na maioria dos mundos próximos ao mundo atual com as mesmas condições iniciais relevantes; (ii) a ocorrência de E tem alguma significação ou importância para algum sujeito $S$ (ou teria importância para S, se ele viesse ter consciência de que E). 
Feitos os esclarecimentos sobre a concepção modal do conceito de sorte, podemos agora tratar do problema crucial: a relação entre sorte e conhecimento.

\section{Sorte Epistêmica}

Agora iremos discriminar diferentes tipos de sorte, a fim de identificar as variedades benignas e malignas de sorte. Devemos isolar a sorte epistêmica propriamente dita, que se manifesta quando S acredita verdadeiramente que $\mathrm{P}$ por sorte ou acidente, das seguintes outras variedades:

Sorte evidencial - S tem sorte em possuir evidência;

Sorte de conteúdo - É uma sorte que p;

Sorte cognitiva - $\mathrm{S}$ tem sorte em obter o conhecimento de que $\mathrm{p}$;

Sorte de faculdade - $\mathrm{S}$ tem sorte em possuir a faculdade cognitiva que permite $\mathrm{S}$ saber que $\mathrm{p}$.

As quatro variedades acima de sorte são benignas, de um ponto de vista epistêmico. Nenhuma delas impede ou cancela a aquisição de conhecimento. Seria absurdo dizer que eu não posso saber que não fui atropelado por um carro hoje à tarde, simplesmente porque tive sorte em não ser atropelado. Trata-se de um caso de sorte de conteúdo. Um caso de sorte evidencial ocorre, por exemplo, quando um detetive tem sorte em obter a evidência que indica o assassino; um caso de sorte cognitiva aconteceria se eu viesse a ter sorte em obter o conhecimento de qual foi o bilhete premiado na loteria (a fim de poder resgaste o prêmio em dinheiro).

Muitos dos conhecimentos que temos envolvem diferentes formas de sorte benigna, conforme vimos logo acima. Pois bem, se nenhuma das formas de acidentalidade ou sorte que vimos acima é epistemicamente maligna, então que tipo de sorte ou acidente é incompatível com a posse de conhecimento? Ora, o tipo maligno de sorte consiste na sorte em obter uma crença verdadeira, dadas as condições iniciais relevantes da situação, o que Pritchard (2005) também denomina de sorte verídica. Dadas as considerações que fizemos, podemos agora fazer uma apresentação preliminar do conceito de sorte epistêmica: 
Condição anti-sorte (CAS) - a crença verdadeira de um sujeito $S$ de que $\mathrm{P}$ em um mundo w é um caso de sorte epistêmica se e somente se a crença de $\mathrm{S}$ de que $\mathrm{p}$ é falsa em uma ampla classe de mundos possíveis próximos ao mundo $\mathrm{w}$ em que as condições iniciais relevantes para a formação da crença são as mesmas.

Conforme veremos a seguir, CAS sugere que a cláusula responsável pela exclusão da sorte verística deve ter a forma de uma condição modal.

\section{O princípio de segurança}

Diferentes autores tem proposto, ao longo das últimas décadas, que uma das condições necessárias para a posse ou presença de conhecimento é a denominada cláusula da segurança ${ }^{8}$. A ideia básica é relativamente clara: um sujeito $S$ sabe que $p$ somente se $S$ não acreditaria facilmente e falsamente que $\mathrm{p}$. Uma crença de que p é segura para um sujeito $\mathrm{S}$ quando, ao formar a crença de que $\mathrm{p}$, o sujeito $\mathrm{S}$ não corre risco de crer falsamente.

Vejamos alguns exemplos a fim de tornar mais concreta esta ideia. Comparemos duas situações. Eu vejo meu amigo e penso: lá está meu amigo João. Meus órgãos sensoriais funcionam normalmente, eu sei como meu amigo se parece, estou vendo em boas condições de iluminação e distância e assim por diante. Minha crença é segura: dadas as circunstâncias em que me encontro, seria muito difícil de me enganar a este respeito. Eu não corro risco elevado de me enganar. Muitas coisas deveriam ser diferentes para que eu acreditasse que meu amigo João está lá e ainda assim João não estivesse lá.

Consideremos agora uma outra situação levemente diferente. Eu vejo meu amigo e formo a crença: lá está meu amigo João. Como no exemplo anterior, estou vendo o próprio João e meus órgãos sensoriais funcionam apropriadamente. Todavia, existe uma diferença importante neste segundo exemplo. João possui um irmão gêmeo, denominado Carlos, cuja existência eu desconheço, e que circula pelo mesmo ambiente e

\footnotetext{
${ }^{8}$ Defesas da condição de segurança são bastante populares e podem ser encontradas em diferentes autores. Sosa defendeu condição de segurança, com formulações ligeiramente diferentes, em Sosa (1999a), Sosa (1999b) e Sosa (2002). Pritchard defendeu que a condição de segurança em diversos lugares, especialmente em Pritchard (2005). Williamson (200o) também defendeu uma variação da condição da segurança, ainda que não no contexto de uma análise do conhecimento.
} 
região. Minha crença de que estou vendo João não é segura: existe um mundo ou circunstância muito próximo onde eu formo a crença de que estou vendo meu amigo João e é falso que João está lá, a saber, o mundo próximo em que estou vendo Carlos, o que facilmente poderia ter acontecido, dado que ele circula pelo mesmo ambiente. Ao formar a crença do modo como eu a formei, eu não estou imune ao risco: eu poderia facilmente me enganar.

Pritchard apresenta uma versão preliminar da condição de segurança (o princípio $S_{1}$ ), e oferece sucessivos enfraquecimentos do princípio inicial (os princípios $S_{2}$ e $S_{3}$ ), a fim de responder a certas objeções. Posteriormente, esta condição de segurança, suficientemente refinada, será combinada com uma cláusula de habilidade. A seguir, irei primeiro introduzir a versão inicial da segurança, com a respectiva motivação, e posteriormente as sucessivas modificações e alterações.

Pritchard inicialmente caracteriza segurança da seguinte forma ${ }^{9}$ :

A crença verdadeira de S é segura sse na maioria dos mundos possíveis próximos em que $S$ continua a formar sua crença a respeito da proposição alvo da mesma forma que o faz no mundo atual, a sua crença continua verdadeira (PRITCHARD, 20o8, p.32).

Vamos dizer que esta versão inicial da condição segurança é o princípio $S_{1}$. Existe um paralelo entre a condição de segurança e o princípio anti-sorte, pois $S_{1}$ e CAS são equivalentes, desde que a forma como $S$ veio a crer que $\mathrm{p}$ seja identificada com as condições iniciais relevantes para a formação da crença. Por conseguinte, o princípio de segurança é justamente o princípio que identifica a condição anti-sorte, responsável pela geração do problema de Gettier. Se aceitamos que o conhecimento exclui a intervenção da sorte epistêmica, o que é um lugar comum na epistemologia, então devemos também aceitar o princípio de segurança ${ }^{10}$.

\footnotetext{
${ }^{9}$ Todas as citações contidas neste artigo foram traduzidas do original em inglês por mim.

${ }^{10}$ A tese de que conhecimento é incompatível com crença verdadeira com sorte epistêmica, embora predominante, não é unânime. Uma divergência importante pode ser encontrada em Hetherington (1998, 2001).
} 
L. R. Rodrigues - Um problema para a epistemologia anti-sorte de Pritchard | 691

\section{Refinamentos da condição de segurança}

Em razão de diversos problemas encontrados para as primeiras versões da condição de segurança, Pritchard produziu sucessivas modificações e refinamentos da primeira proposta.

Consideremos uma dificuldade enfrentada por $\mathrm{S}_{1}$ : o problema da loteria. Consideremos o seguinte exemplo, que denominarei de loteria ${ }_{1}$. S comprou um bilhete $i$ para uma loteria justa, que contém muitos bilhetes, todos com as mesmas chances de serem sorteados. O sujeito $\mathrm{S}$, em razão da elevadíssima probabilidade de que seu bilhete não seja sorteado, forma a crença de que PL, quando $P L=o$ bilhete $i$ não foi sorteado. Por hipótese, PL é verdadeira, e o bilhete $i$ não foi sorteado.

O problema que o exemplo coloca para a teoria de Pritchard consiste no fato de que uma vez que as probabilidades são massivamente contrárias ao sorteio do bilhete, parece que na maioria dos mundos próximos em que as condições iniciais do exemplo são mantidas, o bilhete não é sorteado. Apenas em uma fração pequena dos mundos próximos relevantes a crença de $S$ de que o bilhete não foi sorteado é falsa. Consequentemente, a crença de $\mathrm{S}$ de que seu bilhete não foi sorteado é segura. Todavia, nós gostaríamos de dizer que $S$ não sabe que o seu bilhete não foi sorteado.

Nas palavras de Pritchard,

O exemplo da loteria diz respeito a crença de alguém - anterior à escuta do resultado do sorteio e baseada nas probabilidades [odds] envolvidasde que possui um bilhete perdedor para uma loteria justa, para a qual muito bilhetes foram lançados. Intuitivamente, este não é um caso de conhecimento, apesar das excelentes bases estatísticas que se possui em favor da crença porque, mesmo quando a crença é verdadeira, é uma questão de sorte que ela é verdadeira. Afinal de contas, existem mundos possíveis próximos em que a crença é falsa (i.e., aqueles mundos em que o sujeito possui o bilhete vencedor) (PRITCHARD, 2008, p.36).

Assim, de acordo com Pritchard, a crença verdadeira S de que o bilhete i não foi sorteado, quando a probabilidade de o bilhete i não ser sorteado é extremamente alta, e $S$ acredita que $i$ não foi sorteado com base exclusivamente nas probabilidades envolvidas, envolve sorte epistêmica. Portanto, devemos abandonar a ideia de que segurança elimina sorte 
epistêmica ou bem devemos aceitar que a formação da crença verdadeira de S de que não ganhou na loteria não envolve sorte epistêmica.

Para resolver estas questões, Pritchard sugere que elaboremos uma versão de segurança mais restritiva. Inicialmente, ele sugere a seguinte modificação, que denominaremos $\mathrm{S}_{2}$ : "A crença de $\mathrm{S}$ é segura se e somente se em todos (ou quase todos) os mundos possíveis próximos em que $\mathrm{S}$ continua a formar sua crença na proposição-alvo da mesma forma que faz no mundo atual, a crença é verdadeira” (PRITCHARD, 2008, p.38).

De acordo com ele, a crença de que o bilhete $i$ não foi sorteado na loteria não é verdadeira em todos (ou quase todos) os mundos possíveis próximos em que $S$ forma a respectiva crença. Embora a crença de $S$ que i possa ser verdadeira na maioria dos mundos próximos em que $S$ acredita que $i$, a crença de $S$ de que $i$ não é verdadeira em todos (ou quase todos) os mundos possíveis próximos em que $S$ acredita que $i$. Afinal, existe um mundo possível próximo, um mundo no qual, p.ex., as bolas do sorteio caem em uma configuração diferente, no qual o sujeito $\mathrm{S}$ forma a crença alvo da mesma forma, e ainda assim a sua crença é falsa ${ }^{11}$.

$\mathrm{O}$ princípio $\mathrm{S}_{2}$ se propõe a resolver o problema gerado pelo exemplo da loteria. Contudo, ao resolver um problema, parece que produzimos outro. O motivo é que $\mathrm{S}_{2}$ é vulnerável a certos contraexemplos envolvendo conhecimento indutivo.

Consideremos o seguinte exemplo que foi introduzido por Sosa (1999b), e que denominaremos de caso da lixeira. Do último andar do meu prédio, através de um compartimento, eu jogo um saco de lixo, o qual atravessa um duto, cai diretamente na lixeira do prédio, e é recolhido por ela. Este mecanismo funciona muito bem e com regularidade. Suponhamos que eu acabei de jogar o lixo através do compartimento, e que tudo funcionou como sempre tem funcionado.

Eu sei que o lixo caiu na lixeira, logo após joga-lo pelo compartimento? Aparentemente sim, especialmente se o mecanismo tem funcionado com regularidade, e não há nada de anormal ou estranho na

\footnotetext{
${ }^{11}$ É importante salientar que o mundo em que as bolas do sorte caem em uma configuração diferente é considerado próximo apenas se mantermos fixas as condições iniciais, as quais incluem, entre outras coisas, as leis da física, o número de bolas no sorteio, e aleatoriedade do sorteio e assim por diante.
} 
situação. Todavia, isto parece gerar certos problemas para a teoria inicial de Pritchard $^{12}$ :

Considere novamente, por exemplo, o 'caso da lixeira' descrito por Sosa, e que foi citado acima. Intuitivamente, nós queremos dizer que Sosa sabe que o seu saco de lixo alcançou o chão. O problema é que se segurança é entendida de forma robusta na linha de $\left(\mathrm{SP}^{*}\right)$ [a condição $\mathrm{S}_{2}$ ], então, foi alegado, este conhecimento parece excluído, uma vez que certamente existem alguns poucos mundos possíveis, i.e., aqueles nos quais o saco fica preso ao longo do caminho, nos quais Sosa continua a formar a crença na mesma proposição e ainda assim forma uma crença falsa como resultado (PRITCHARD, 2008, p.38).

Para acomodar estas duas intuições, de que temos crença segura no caso da lixeira e crença insegura no caso da loteria, Pritchard propõe esta outra modificação da condição de segurança, que denominaremos $\mathrm{S}_{3}$ :

A crença de $S$ de que P é segura no mundo atual se e somente se na maioria dos mundos próximos [nearby] em que $\mathrm{S}$ continua a formar a sua crença a respeito da proposição-alvo da mesma forma que o faz no mundo atual, e em todos os mundos muitos próximos [very close nearby worlds] em que $\mathrm{S}$ forma a sua crença a respeito da proposição-alvo da mesma forma que o faz no mundo atual, a sua crença continua sendo verdadeira (PRITCHARD, 2008, p.40).

A ideia básica de $\mathrm{S}_{3}$ é que não pode existir um único mundo muito próximo ao mundo atual em que $\mathrm{S}$ crê p e é falso que p. Ao mesmo tempo, no que diz respeito aos mundos próximos (porém não muito próximos) em que $S$ acredita que $\mathrm{p}$, é suficiente que seja verdadeiro que $\mathrm{p}$ na maior parte deles. De acordo com Pritchard, a segunda cláusula explica porque não temos conhecimento no caso da loteria, visto que existe, ao menos, um mundo muito próximo que $S$ forma uma crença falsa a respeito da proposição-alvo, a saber, o mundo em que as bolas do sorteio caem em uma configuração ligeiramente diferente, fazendo com que o bilhete $S$ seja o bilhete vencedor. Contudo, a combinação da primeira com a segunda cláusula não é incompatível com o conhecimento no caso da lixeira, desde

\footnotetext{
12 Talvez alguém respondesse ao problema levantado pelo problema lixeira para o princípio $\mathrm{S}_{2}$ simplesmente aceitando que não temos conhecimento indutivo, ou que temos muito menos conhecimento indutivo que normalmente pensamos ter. Filósofos inclinados ao ceticismo indutivo, talvez já motivados a pensar desta forma por outras razões, poderiam muito bem aceitar esta implicação, e manter o princípio $S_{2}$. Trata-se de uma crítica pertinente à argumentação de Pritchard, conforme foi apontado pelo avaliador B.
} 
que não exista um único mundo muito próximo em que $S$ acredita que p e é falso que $\mathrm{p}$, e que na maioria dos mundos próximos em que $S$ forma a crença a respeito da proposição nas mesmas condições, a crença de $S$ é verdadeira.

Conforme vimos, o motivo pelo qual Pritchard julga que $\mathrm{S}_{3}$ dá a resposta correta ao problema da loteria é que ele considera que o mundo possível próximo em loteria ${ }_{1}$, em que é falso que o bilhete foi sorteado é um mundo possível muito próximo. A razão pela qual este mundo deve ser categorizado entre os mundos muito próximos, é que muito pouco precisaria ser mudado no mundo atual, para que a crença de que PL viesse a ser falsa. Apenas precisaria acontecer que as bolas numeradas do sorteio, supondo o mecanismo tradicional de muitas loterias, viesse a cair em uma configuração ligeiramente diferente. E isto, pelo menos segundo o autor, ocorre em mundos muito próximos.

Uma consequência interessante da resposta de Pritchard ao problema da loteria é que ela implica o divórcio entre as noções de probabilidade e distância modal. Eventos muito improváveis no mundo atual, tal como vir a ganhar em uma loteria, podem ser modalmente muito próximos. Consequentemente, a distância modal não deve ser função da probabilidade de um evento ocorrer.

\section{A crítica de McEvoy}

Em artigo recente, McEvoy (2009) propôs uma crítica penetrante à Pritchard, e sugeriu que o autor não conseguiu solucionar apropriadamente o problema que vimos no capítulo anterior. A seguir, irei apresentar esta crítica, e tecer alguns comentários em seu favor.

Consideremos agora a seguinte variação do exemplo da loteria. Denominaremos ela de loteria ${ }_{2}$. S comprou um bilhete i para uma loteria justa, que contém muitos bilhetes, todos com as mesmas chances de serem sorteados. Após a realização do sorteio, é divulgado o resultado: o bilhete de S não foi sorteado. Após ler no jornal local, que em linhas gerais é confiável e não costuma errar a respeito desse tipo de assunto, $\mathrm{S}$ forma a crença verdadeira de que seu bilhete não foi sorteado.

Em loteria ${ }_{1}$, diríamos que $S$ não sabe que o seu bilhete não foi sorteado antes de verificar por algum outro meio (ninguém sabe que um bilhete de loteria não foi sorteado, simplesmente com base nas 
probabilidades envolvidas). Em loteria ${ }_{2}$, diríamos que o sujeito possui conhecimento. Parece se tratar de um caso normal de conhecimento testemunhal

Todavia, apesar de loteria ${ }_{2}$ parecer envolver um caso normal de conhecimento testemunhal, não é o que a teoria de Pritchard nos levaria a dizer. McEvoy alega que a crença de que PL em loteria ${ }_{2}$ não é segura, de acordo com $\mathrm{S}_{3}$. O mesmo motivo que conduz Pritchard a dizer que a crença de que PL não é segura em loteria ${ }_{1}$, também deveria levar Pritchard a dizer que a crença de que PL em loteria ${ }_{2}$ não é segura. Afinal, para que o sujeito $S$ viesse a crer falsamente em loteria ${ }_{2}$, tudo o que precisaria acontecer seria que houvesse um deslize da parte do jornal. O evento em que $\mathrm{S}$ crê falsamente que ganhou na loteria porque um número foi acidentalmente trocado não parece exigir uma mudança significativa em relação ao mundo em que, por hipótese, o jornal relata corretamente o resultado do sorteio.

A réplica mais natural em defesa de $S_{3}$ seria dizer que, dado que o jornal é bastante confiável e possui algum tipo de mecanismo para detecção de erros, o mundo possível próximo em que um erro passa despercebido pelos mecanismos de correção deve ser considerado suficientemente distante. Segundo tal réplica, este mundo em questão não é um mundo muito próximo.

Pritchard alega que jornais, pelo menos aqueles que merecem crédito, possuem certos mecanismos destinados a prevenção de erros deste gênero. Existem editores e revisores de texto, geralmente confiáveis, que trabalham para que tais falhas não aconteçam. Conforme coloca o autor:

O ponto aqui é que jornais confiáveis - o tipo de jornal que alguém pode usar para vir a saber que perdeu na loteria - possuem mecanismos de correção internos que visam prevenir tais tipos de erro de digitação ou impressão de virem a ocorrer. A equipe é altamente treinada e diligente, toda informação é corrigida duas vezes por eficientes revisores de texto, e, talvez mais significativamente, aqueles que conferem os resultados são provavelmente possuidores de bilhetes de loteria, e possuem um interesse pessoal na correção dos resultados. Em suma, eu penso que uma vez que descrevemos os detalhes do caso apropriadamente, não é muito plausível supor que os mundos possíveis onde nosso herói forma uma crença falsa na proposição alvo são próximos (PRITCHARD, 2009, p.36). 
Pritchard sugere, na passagem acima citada, que se descrevermos corretamente os detalhes envolvidos no caso, veremos que os mundos possíveis nos quais o jornal erra não são muito próximos. No entanto, existe uma objeção importante de McEvoy a esta réplica de Pritchard.

A objeção de McEvoy parte da constatação de que, afinal de contas, erros deste tipo ocorrem em jornais tipicamente confiáveis, ainda que não com grande frequência (se fossem excessivamente frequentes, então os jornais não seriam mais propriamente confiáveis). Tudo o que seria necessário para que o sujeito acreditasse falsamente em loteria ${ }_{2}$ seria que o jornal cometesse um erro ao relatar o resultado, e que o mecanismo de correção (confiável, porém falível) viesse a falhar, talvez por um lapso do corretor de texto do jornal. Conforme coloca o autor:

O ponto destes exemplos é que impressão errada e outros erros podem e, de fato, ocorrem em jornais normalmente confiáveis. O fato de que erros de impressão ocorrem, apesar das boas qualidades dos jornalistas e revisores, mostra que tais erros podem ocorrer sem exigir modificações transmundanas relativamente às qualidades dos agentes relevantes. Por que pensar que os relatos dos vencedores de sorteios de loteria seriam especialmente imunes a tais erros? A falibilidade dos funcionários dos jornais é tudo que é necessário para erros aconteçam em qualquer área. (MCEVOY, 2009, p.14).

Erros são encontrados diariamente em jornais confiáveis no mundo atual. Se este é o caso, não deveríamos dizer que a possibilidade de erro do jornal deve ser considerada muito próxima, uma vez que casos muito semelhantes sob tos aspectos relevantes ocorrem no mundo atual? Afinal de contas, é duvidoso, para dizer o mínimo, que o mundo em que o jornal comete um erro ao relatar o resultado da loteria não é muito similar ao mundo atual, se situações muito similares, pelo menos sob os aspectos relevantes (o jornal é confiável em grau semelhante, existem mecanismos para prevenção de erros, e assim por diante), já fazem parte do mundo atual.

Mesmo jornais confiáveis já erraram em situações semelhantes ao mundo atual, e muitos até mesmo possuem sessões específicas onde tais erros são reconhecidos. Considerando o que vimos até aqui, um mundo em que o jornal em questão erra ao relatar o resultado do loteria deve ser considerado muito próximo do mundo atual, supondo que o mundo atual 
seja um mundo em que o jornal em questão não erra ao fazer este relato específico.

Agora podemos retomar a alegação de Pritchard de que verificamos que o mundo onde o jornal erra não é muito próximo, desde que o exemplo seja descrito com suficiente riqueza de detalhes. O motivo pela qual a réplica de Pritchard não é efetiva pode ser analisado à luz da objeção de McEvoy. Nenhuma descrição do exemplo conseguirá apagar o fato de que o jornal é falível, e que falhas em circunstâncias muito semelhantemente relevantes ocorrem no mundo atual (em outros jornais ou no mesmo jornal) ${ }^{13}$. Desta forma, a alegação de que uma descrição adequada da situação poderia revelar que se trata de crença segura não se mostra viável.

Podemos extrair das considerações até aqui feitas duas linhas de argumentação contra a tese de Pritchard de que $S$ possui conhecimento em Loteria ${ }_{2}$. A primeira delas simplesmente se baseia na ideia de falibilidade: o jornal é falível, e o mundo em que o jornal falível vem a errar parece suficientemente próximo. A segunda linha depende da tese bastante plausível de que se jornais (o jornal em questão ou outros) cometem erros em situações muito relevantes no mundo atual, então o mundo possível em que o jornal específico do exemplo comete erros ao relatar resultados de loteria deve ser também considerado muito próximo ao mundo atual. Conforme vemos, o problema do argumento de Pritchard é que ele parece exigir demais da confiabilidade, e do que esperaríamos de um jornal ou de outra fonte de informação semelhante.

Curiosamente, uma versão anterior da condição de segurança, o princípio $S_{1}$, parece responder corretamente a loteria $a_{2}$. Afinal, ainda que exista algum mundo possível muito próximo em que o jornal erra ao relatar o resultado, isto não parece ocorrer na maioria deles ou com grande frequência. O problema desta alternativa é que, em razão de

\footnotetext{
${ }^{13}$ Alguém poderia objetar que o mundo possível em que o jornal erra é próximo, porém não muito próximo. Quanto a esta objeção, sugerida pelo avaliador B, há algumas considerações a ser feitas. Tudo o que precisaria acontecer, para que o jornal viesse a cometer tal erro, seria uma pequena falha dos mecanismos de correção, eles mesmos falíveis. O mundo em que isto acontece não é muito diferente do mundo atual, e pequenos deslizes, de mecanismos muito confiáveis porém falíveis, não parecem exigir grandes mudanças em relação ao mundo atual, mesmo considerando todos os detalhes do exemplo sugeridos por Pritchard. Muito precisaria mudar para que um competente e diligente editor deixasse passar uma número ou letra incorreta? Afinal de contas, exemplos que correspondem exatamente a esta descrição já são encontrados no mundo atual. Por fim, gostaria apenas de apontar que Pritchard não fornece um critério para distinguir mundos muito próximos de mundos muito próximos, o que pode contribuir para eventuais divergências acerca de como julgar casos individuais.
} 
loteria ${ }_{1}$, Pritchard se viu obrigado a rejeitar $S_{1}$. Não penso haver uma saída viável, no quadro dos princípios sugeridos por Pritchard.

\section{Por que a incapacidade de responder ao exemplo da loteria ${ }_{1}$ é problemática?}

Conforme vimos, Pritchard defende uma epistemologia anti-sorte modesta. Se este é o caso, ele não poderia simplesmente alegar que existe alguma outra condição necessária adicional para o conhecimento, que não é satisfeita em loteria ${ }_{1}$ ? Tal resultado enfraqueceria o poder explicativo da condição de segurança, e, por conseguinte, a sua força argumentativa. Em todo caso, isto não seria suficiente para forçar a rejeição da teoria, uma vez que as outras razões em favor da teoria permaneceriam intactas.

Esta não é uma saída atraente para Pritchard. Eis como ele explica seus motivos, referindo-se ao exemplo que denominamos loteria ${ }_{1}$ :

Um tipo de resposta pode consistir em suplementar as teorias da segurança do conhecimento com outras condições epistêmicas que podem, em conjunção com a segurança, tratar do caso. O problema com esta proposta, entretanto, é que uma vez que a intuição guia aqui é que conhecimento está faltando precisamente por causa da presença de sorte, e uma vez que, como nós notamos, (SP) [o princípio S1] é uma maneira natural de entender a condição anti-sorte, este movimento dialético não é muito atraente. (PRITCHARD, 2008, p.38).

Claramente, Pritchard considera que uma resposta aos casos de loteria é essencial. Sem um tratamento do problema, ele considera que a segurança perde a sua principal razão de ser: a capacidade de capturar a condição anti-sorte. Como Pritchard não consegue produzir o resultado correto em loteria ${ }_{1}$ sem produzir o resultado incorreto em loteria ${ }_{2}$, é difícil encontrar uma saída satisfatória. A teoria está em um beco sem saída.

Existe, contudo, um segundo problema. Pritchard julgou necessário acrescentar uma condição de habilidade à sua condição antisorte. Embora eu não queira me aprofundar nos detalhes a este respeito por não ser este o foco do presente trabalho, é pertinente fazer uma explicação. Ele defende o seguinte princípio, que combina a segurança da crença com a ideia de que a formação da crença verdadeira deve ser creditada, em larga medida, ao exercício das habilidades cognitivas do agente: 
$\mathrm{S}$ sabe que $\mathrm{P}$ se e somente se a crença segura de $\mathrm{S}$ de que p é o produto das suas habilidades cognitivas relevantes (tal que o seu sucesso cognitivo é em um grau suficientemente alto creditável à sua agência cognitiva) (PRITCHARD, 2012b, p.273).

O problema é que, segundo o autor, a condição de habilidade isoladamente (sem referência à segurança da crença) não explica a ignorância do sujeito. A epistemologia da virtude forte, que afirma que formação de uma crença verdadeira em razão do exercício de uma habilidade cognitiva é suficiente para distinguir conhecimento de crença verdadeira, não consegue explicar a ignorância do sujeito. Conforme ele mesmo escreve:

\footnotetext{
Em primeiro lugar, note como a epistemologia da virtude forte luta com o caso da loteria. Afinal de contas, o sucesso cognitivo de Lottie [nome que Pritchard dá ao personagem de um exemplo semelhante à loteria ${ }_{1}$ ] parece ser explicado pelo exercício de suas habilidades cognitivas relevantes, não parece? Dito de outra forma, se não é a habilidade cognitiva de Lottie que explica seu sucesso cognitivo, então o que o explica? Pois note que o único candidato plausível aqui é a boa sorte (epistêmica) de que seu bilhete seja o bilhete perdedor. (PRITCHARD, 2012b, p.266).
}

Em vista disso, os problemas parecem ainda mais graves. Pritchard pensa - com al- guma plausibilidade - que o sucesso cognitivo (formação de crença verdadeira) é, de alguma forma, explicado pelo exercício de habilidades cognitivas do agente. Se este é o caso, então a única maneira de compatibilizar a ignorância do sujeito $\mathrm{S}$ em loteria ${ }_{1} \mathrm{com}$ epistemologia da virtude anti-sorte seria alegar que a crença não é segura. Todavia, este não pode ser o caso, conforme vimos anteriormente. Consequentemente, se aceitarmos a epistemologia da virtude anti-sore, e que as condições de habilidades e anti-sorte são satisfeitas, então teríamos de aceitar que em loteria ${ }_{1}$ o sujeito $S$ sabe que o bilhete i não foi sorteado, o que é simplesmente absurdo.

\section{Por que loteria ${ }_{1}$ não é um caso de sorte epistêmica?}

Pritchard afirma explicitamente que a ignorância do sujeito $\mathrm{S}$ em situações do tipo loteria ${ }_{1}$ é explicada pela sorte epistêmica. A seguir, irei sugerir que isto não pode ser correto. Todavia, como Pritchard considera 
essencial que a condição de segurança explique a ignorância do sujeito loteria ${ }_{1}$, em razão da condição de habilidade não explicar a ignorância do sujeito, a questão se revela de máxima importância. Para ilustrar o ponto, e apresentar a natureza do problema, iremos considerar o seguinte caso, uma variação dos exemplos anteriores de loteria, que denominaremos de loteria inversa.

Um sujeito S compra um bilhete de loteria, digamos o bilhete i, a fim de receber um prêmio em dinheiro. As características da loteria são da seguinte: (a) o número de bilhetes em disputa é extremamente alto, tão elevado quanto quisermos imaginar; (b) a loteria é justa, e todos os bilhetes possuem exatamente a mesma chance de serem sorteados; (c) a pessoa que comprou um bilhete e foi sorteada não receberá o prêmio em dinheiro; (d) a cada bilhete não sorteado corresponderá um prêmio, igual para todos os bilhetes, que poderá ser resgatado por seu possuidor.

Pois bem, a loteria foi rodada, o bilhete i não foi sorteado e $S$ recebeu o prêmio em dinheiro. Diríamos que $S$ teve sorte em ganhar o prêmio? Eu penso que a resposta é justamente negativa: o sujeito $S$ não teve sorte em loteria inversa. O que parece explicar isto é certa conexão entre os conceitos de normalidade e de sorte. Quando ocorre o que normalmente ocorre - e que esperávamos que acontecesse nas circunstâncias descritas - nós relutamos em dizer que o evento em questão é um caso de sorte, ou que o sujeito beneficiado pelo evento teve sorte. Quando dizemos que alguém teve sorte, supomos normalmente tratar-se de eventos que são, em alguma medida, excepcionais e não previsíveis. A implausibilidade da afirmação de que eventos regulares podem ser considerados casos de sorte é observada com maior claridade quando notamos a aparente incongruência, e desconforto, que nos trazem sentenças do tipo: $P$ é um caso de sorte e P ocorre regularmente.

Ao afirmar a conexão entre as noções de sorte, regularidade e normalidade, não estou alegando que estas condições devem fazer parte de uma análise do conceito de sorte, pois elas podem não podem ser condições suficientes. Podem haver cláusulas adicionais, as quais deveriam ser incluídas em uma análise do conceito de sorte. O que meramente afirmo é que eventos que ocorrem regularmente não são considerados casos de sorte, e isto explica porque relutamos em dizer que o sujeito $\mathrm{S}$ teve sorte no caso loteria inversa. Tampouco consideramos que um evento E é um caso de sorte quando, dado tudo o que sabíamos sobre a situação 
antes do evento $\mathrm{E}$, o que racionalmente esperávamos é que justamente $\mathrm{E}$ acontecesse. A tese de Pritchard de que a ignorância do sujeito em loteria deve ser explicada pela noção de sorte epistêmica se mostra profundamente contraintuitiva.

Note-se como o caso da loteria inversa, e o diagnóstico que propomos para o caso, colocam a teoria de Pritchard em sérias dificuldades. Os mesmos motivos que nos levaram a julgar que $S$ não teve sorte no caso da loteria inversa também deveriam, para todos os efeitos, nos levar a afirmar que em Loteria $a_{1}$ a crença verdadeira $S$ de que o seu bilhete não foi sorteado não é verdadeira por sorte ou acidente. Não atribuímos sorte a tipos de eventos que ocorrem com excepcional regularidade, e que correspondem ao que normalmente ocorre. Se este é o caso, então a formação de uma crença verdadeira por parte de $S$ não deve ser explicada pela sorte verídica; afinal de contas, que o sujeito viesse a crer verazmente, dadas as circunstâncias em que a crença foi formada, é o precisamente o esperaríamos que acontecesse neste caso (o que normalmente acontece), e o que regularmente acontece nestas circunstâncias.

Assim, da mesma forma que um sujeito $S$ não teve sorte em ter seu bilhete não sorteado, quando a probabilidade de ele vir a ser sorteado é extremamente pequena, também não teve sorte o sujeito que veio a crer verazmente que o seu bilhete não foi sorteado com base nas probabilidades envolvidas, quando a probabilidade de ele vir a sorteado é mínima. Qualquer que seja a razão que explica nossa relutância em atribuir conhecimento a S em loteria inversa - não é minha intenção disputar essa inclinação - ela deve ser procurada em outro lugar. Visto que a condição de segurança é a cláusula anti-sorte por excelência, de acordo com Pritchard, e que a ignorância do sujeito em loteria inversa não é explicada pela sorte epistêmica, parece que a condição de segurança não consegue responder ao exemplo. Resultado semelhante acontece com o sujeito que crê que seu bilhete não será sorteado em loteria ${ }_{1}$, visto que a diferença entre os dois casos diz respeito apenas aos prêmios envolvidos, e não à probabilidade dos bilhetes serem sorteados ${ }^{14}$. Considerando que a

\footnotetext{
${ }^{14} \mathrm{O}$ avaliador B notou corretamente que, tanto em loteria inversa como em Loteria ${ }_{1}$, os sujeitos envolvidos não possuem conhecimento. Com efeito, as considerações que fiz sobre o caso da loteria inversa também são aplicáveis mutatis mutandis ao caso da loteria. Todavia, como ignorância do sujeitos em ambos os casos não parece ser explicada pela condição de habilidade nem pela sorte epistêmica, a teoria de Pritchard se encontra diante de um problema em ambos os casos. O exemplo da loteria inversa foi elaborado apenas para ilustrar como regularidade,
} 
condição da habilidade não gera um resultado melhor, segundo o próprio autor, temos que a sua epistemologia da virtude anti-sorte, tal como proposta pelo autor, não tem meios de tratar adequadamente ao caso da loteria $_{1}$.

\section{Conclusão}

Nós vimos, neste artigo, as linhas gerais da epistemologia antisorte de Duncan Pritchard, e algumas das motivações da proposta. Apesar de todas as qualidades da teoria, e de ser a mais ampla e profunda investigação das relações entre sorte e conhecimento, penso que existem três problemas teóricos importante.

O primeiro foi corretamente apontado por Mark McEvoy. O autor defende que a teoria de Pritchard produz o resultado incorreto quando aplicada a um exemplo, que aqui denominamos de Loteria ${ }_{2}$. Trata-se de um aparente caso de conhecimento que, se fôssemos julgar pelos princípios apontados por Pritchard, deveríamos dizer que é um caso de ignorância.

Uma segunda objeção alega que o princípio $S_{3}$ não captura corretamente nossas inclinações sobre exemplos de sorte, o que procurei mostrar através do exemplo da loteria inversa, e das conexões entre sorte e regularidade.

Uma terceira objeção alega que a explicação para a ignorância do sujeito em Loteria ${ }_{1}$ não é a presença de algum tipo de sorte epistêmica. Todavia, é importante, para a proposta de Pritchard, que a ignorância do sujeito seja explicada em termos de sorte. Temos, desta forma, mais uma objeção bastante importante à teoria defendida por Pritchard.

Penso que todas estas considerações sugerem que a teoria da epistemologia da virtude anti-sorte, tal como proposta por Duncan Pritchard, deve ser rejeitada, ou, pelo menos, significativamente reformada. 
L. R. Rodrigues - Um problema para a epistemologia anti-sorte de Pritchard | 703

\section{Referências}

DANCY, J.. An introduction to contemporary epistemology. Oxford: Blackwell,1985.

HETHERINGTON, S. Good knowledge, bad knowledge: On two dogmas of epistemology. Boulder: Clarendon Press, 2001.

HETHERINGTON, S. “Actually knowing”. The Philosophical Quarterly, 48, 193 (1998), p. 453-469.

LEWIS, D.. Counterfactuals. Oxford: Blackwell Publishing, 1973.

MCEVOY, Mark. “The Lottery Puzzle and Pritchard's safety Analysis of Knowledge”. Journal of Philosophical Research, 34 (2009), p. 7-20.

PRITCHARD, D. Epistemic luck. New York, USA: Oxford University Press, 2005.

. Knowledge, luck, and lotteries. In: HENDRICKS, V.; PRITCHARD, D. (org.). New

Waves in epistemology. NY: Palgrave Macmillan, 2008, p. 28-51.

. “Safety-Based Epistemology: whiter now?”. Journal of Philosophical Research, 34 (2009), p. 33-45.

. "Anti-luck virtue epistemology”. The Journal of Philosophy, 109, 3, (2012a), p. 247-279.

. In defense of modest anti-luck epistemology. In: BECKER, K.; BLACK, T.. (Org.). The Sensitivity Principle in Epistemology. Cambridge, UK: Cambridge University Press, 2012b, p. 173-192.

RODRIGUES, L.. As epistemologias modais e seus críticos. 2017. 123f. Tese (Doutorado em filosofia) - Instituto de Humanidades, Pontifícia Universidade Católica do Rio Grande Do Sul (PUCRS), Porto Alegre, 2017

RUSSELL, B. The problems of philosophy. Oxford, UK: Oxford University Press, 2001. . Human knowledge: Its scope and its limits. New York: Simon \& Schuster, 1948.

SHOPE, R. The Analysis of Knowing: A Decade of Research. Princeton, New Jersey: Princeton University Press, 1983.

SOSA, E. "How must knowledge be modally related to what is known?". Philosophical Topics, 26, 1(1999a), p. 373-384.

. "How to defeat opposition to Moore". Philosophical perspectives, 13(1999b), p. 141- 153 .

STALNAKER, R. A Theory of Conditionals. In: Rescher, N (ed.). Studies in Logical Theory. Oxford, UK: Oxford University Press, 1981, p. 98-112. 
704 | Veritas | Porto Alegre, v. 62, n. 3, set.-dez. 2017, p. 683-704

UNGER, P. “An analysis of factual knowledge”. The Journal of Philosophy, 65, 6 (1968), p. 157-170.

WILLIAMSON, T. Knowledge and Its Limits. Oxford, UK: Oxford University Press, 2000.

\section{Endereço Postal:}

Departamento de filosofia Universidade federal da fronteira do sul SC-484 - Fronteira Sul, Chapecó - SC, 89815-899, Brasil

Data de recebimento: 01-09-17

Data de aceite: 05-12-17 